\title{
Alteration of optical and morphological properties of polycarbonate illuminated by visible/IR laser beams
}

\section{Hassan Ehsani}

Saiedeh Saghafi

saghafi@fkeserver.fke.tuwien.ac.at

\section{Mahmoud Ghoranneviss}

\section{Mohamadreza Hantezadeh}

\section{Homa Hosseini}

\section{Hans-Ulrich Dodt}

\author{
Biophotonics Group, Plasma-Physics Research Center, Research Science Campus, Isamic Azad \\ University-IAU, Tehran, Iran \\ Biophotonics Group, Plasma-Physics Research Center, Research Science Campus, Isamic Azad \\ University-IAU, Tehran, Iran \\ Department of Bioelectronics, Institute of solid state Electronics, Vienna University of Technology, Aus- \\ tria \\ Biophotonics Group, Plasma-Physics Research Center, Research Science Campus, Isamic Azad \\ University-IAU, Tehran, Iran \\ Biophotonics Group, Plasma-Physics Research Center, Research Science Campus, Isamic Azad \\ University-IAU, Tehran, Iran \\ Biophotonics Group, Plasma-Physics Research Center, Research Science Campus, Isamic Azad \\ University-IAU, Tehran, Iran
}

Department of Bioelectronics, Institute of Solid State Electronics, Vienna University of Technology, Austria

In this paper we investigate the effects of visible to near infrared (NIR) laser illumination on the optical transmission (OT) and morphological (MC) alterations of thin, curved surfaces of polycarbonate (PC). The second harmonic of Nd:YAC laser ( $532 \mathrm{~nm}$ ) and two diode lasers (665 and $980 \mathrm{~nm}$ ) were used as illuminating sources. The morphological changes of the PC surfaces are determined using atomic force microscopy (AFM), demonstrating the appreciable changes caused by shorter wavelengths (higher energy). When analyzing the OT spectra of PC thin films, a measurable decrease in the OT of the PC samples which were illuminated by 532, 665 and $980 \mathrm{~nm}$, in particular $532 \mathrm{~nm}$, for energy densities greater than $25 \mathrm{~J} / \mathrm{cm}^{2}$ can be seen. [DOI: 10.2971/jeos.2010.10032S]

Keywords: photon, laser, illumination, polycarbonate

\section{INTRODUCTION}

Polycarbonate (PC) is a product of a linear polycondensation reaction, which has a regular structure. Dependent on the moulding conditions, it can be in the crystalline or amorphous state. Only the amorphous polymer has inherently acceptable optical properties [1, 2]. Amorphous PCs have been extensively used to replace the conventional engineering materials (i.e. glasses, metals, etc.) in a wide range of applications such as optical lenses and eye wears [3]. As a result of their excellent breakage resistance, the PCs have been considered as a beneficial replacement for many products, such as automobile headlamps [4].

Bisphenol-A polycarbonate (BPAPC) is one of the foremost types of PCs for the production of various transparent materials, however, factors such as sunlight, humidity and oxygen can degrade the quality of the PCs [5]. When exposing thin surfaces of PC to UV radiation, the polymer exhibits some losses in mechanical properties in addition to changes in optical properties [6]-[10]. Diepens, et al. have performed extensive research on the effect of UV light on BPAPC quality with particular attention being paid to the degradation mechanism at the molecular level [11]. Furthermore, due to the fact that PC is a soft material, it can be easily scratched. Therefore, in many applications in order to improve the mechanical properties of polycarbonate, a deposition of anti-scratch coating on polycarbonate surface is necessary to protect the surface against common handling scratches. $\mathrm{SiO}_{2}$ is coated on the inner surface of our samples as an anti-scratch layer to enhance the mechanical properties [3, 12, 13]. Extensive investigations regarding anti-scratch coating materials, methods and effects of UV photons on them have been undertaken [14]-[16]. However, studying the influence of coherent illumination, particularly visible to infrared, on the optical properties and the morphology of coated PCs has remained a subject of interest. For this purpose, the second harmonics of ND:YAG (532 nm) and two diode lasers (665 $\mathrm{nm}$ and $980 \mathrm{~nm}$ ) have been employed as illuminating sources.

\section{INTERACTIONS BETWEEN POLYCARBONATES AND LASER BEAMS}

Effects such as photo-thermal and photo-chemical ablation or their combination may occur when a polymer is illuminated by a coherent beam [17]-[20]. Ultra-violet photons have sufficient energy to break chemical bonds causing photo-chemical 


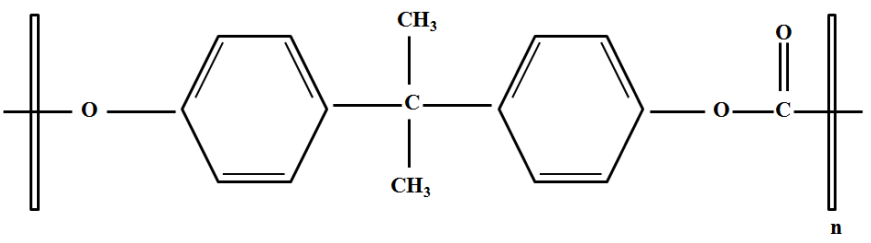

FIC. 1 Repeating unit of Bisphenol-A polycarbonate.

ablation. Additionally, if the surface is irradiated by infrared photons, thermal effects due to the oscillation mode of the molecules may occur. In this case, polymer excitation may happen but dissociation would not occur in monomers. By prolonging the exposure time, collisions between the irradiated monomers and surrounding environment occur. Some monomers could even be ejected due to the photon energy transfer process. However, they would not escape from the cohesive energy between monomer units and may simply produce irregularities at the polymer surface [17]-[20].

The accumulated laser beam dose at the PC surface is given by Eq. (1):

$$
D(t)=\int I(t) A(t) d t
$$

where, $I(t)$ is the laser beam intensity and $A(t)$ is the dynamic absorption coefficient function of the polycarbonate. When the beam incident dose approaches a critical value, polycarbonate surface can be damaged, leading to confinement at the surface.

\subsection{Sample preparation}

The illuminated samples were conventional Bisphenol-A polycarbonate (BPAPC). The length, width and depth of these samples were $20 \mathrm{~mm}, 20 \mathrm{~mm}$, and $2 \mathrm{~mm}$, respectively. The conformational structure and intermolecular arrangement of the BPAPC is represented schematically in Figure 1.

The anti-scratch coating was fabricated by plasma-enhanced chemical vapor deposition on the polycarbonate surface. This technique provides a transparent and very thin (approximately $4000 \mathrm{~nm}$ ) layer. We prepared identical samples, cutting from a curved sheet. The radius of curvature of the curved PC sheet was approximately $6 \mathrm{~cm}$. The thickness of sample is about $2 \mathrm{~mm}$. Ultrasonic cleaning was applied for 15 minutes to clean the surface of these samples. Among our samples, we consider the one which is not exposed to laser beam as the "index" sample.

\subsection{Light sources and optical instruments}

The continuous wave visible lasers used in this study are the second harmonic of $\mathrm{Nd}$ :Yag laser (532 nm, green) and an AlGaInP diode laser ( $665 \mathrm{~nm}$, red). The output power and beam diameter of the second harmonic of Nd:Yag laser is $130 \mathrm{~mW}$ and $\sim 1 \mathrm{~mm}$, respectively. Using a $10 \times$ beam expander, the area cross section becomes $\sim 0.695$.

The red diode laser emits $665 \mathrm{~nm}$ nearly TEM00 beam with beam diameter of $\sim 2 \mathrm{~mm}$. Its output power is $155 \mathrm{~mW}$. Us-

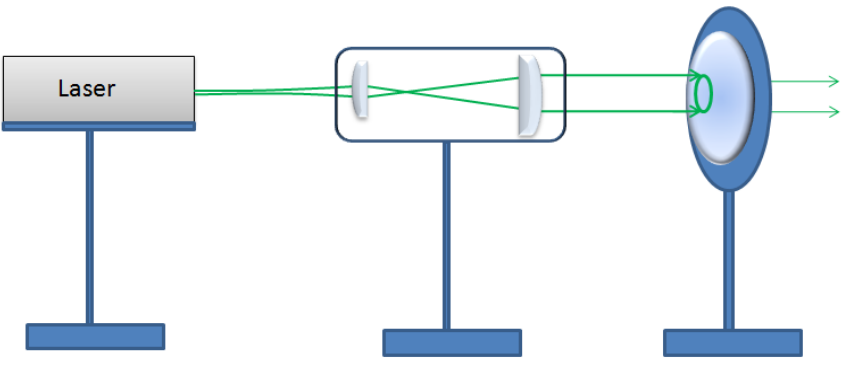

FIG. 2 The experimental set up.

ing a $5 \times$ beam expander (two Plano-convex lenses of 7 and $35 \mathrm{~mm}$ ), the area cross section of this diode laser becomes $\sim 0.695$ (Figure 2).

The third illuminating source is an infrared InGaAsP diode laser. It emits $980 \mathrm{~nm}$ near TEM00 beam and the output power is $140 \mathrm{~mW}$. The output beam diameter at the aperture of the laser is $\sim 2 \mathrm{~mm}$ and the angle of divergence is less than $\sim$ $1.1 \mathrm{mrad}$. Using a $5 \times$ beam expander, the area cross section of this diode laser becomes $\sim 0.695$.

To compare the effects of these three laser beams on the OT and the morphology of polycarbonate surfaces, the incident dose was considered as a key factor. Incident dose is the multiplication of power density (P/A) and time of illumination. The time of illumination for $532 \mathrm{~nm}, 665 \mathrm{~nm}$, and $980 \mathrm{~nm}$ beams are $90 \mathrm{sec}, 75.5 \mathrm{sec}$, and $83.5 \mathrm{sec}$, respectively. It provides an incident dose of $16.80 \mathrm{~J} / \mathrm{cm}^{2}$. In following experiments, we have increased the incident dose by factor of 1.5 and 3 by changing the spot size of lasers beams (using different beam expander) or irradiation time. The information regarding the lasers spot size for various energy densities $\left(16.8 \mathrm{~J} / \mathrm{cm}^{2}, 25.2 \mathrm{~J} / \mathrm{cm}^{2}\right.$ and $\left.50.30 \mathrm{~J} / \mathrm{cm}^{2}\right)$ are tabulated in Tables 1-3. A Spectrophotometer model "Cary 500 Scan" was used to characterize the effects of various wavelengths on OT. Additionally, changes in surface morphology were studied using atomic force microscopy (Instrument model "Nano surfmobile $\left.S^{\prime \prime}\right)$.

\section{RESULTS AND DISCUSSION}

\subsection{Transmission spectra}

Photo-degradation of each PC surface was monitored using Cary 500 Scan UV-IR spectrophotometer (200-1400 nm). The OT of the samples are dependent on the incident dose. It is controlled by the output power of the radiation source, the irradiation area and the time of exposure. The OT spectra of all samples (index and illuminated) for energy density of $16.80 \mathrm{~J} / \mathrm{cm}^{2}$ are shown in Figure 2. The changes in the OT of the illuminated samples are much more significant compared with the index samples. Peaks and troughs in the index and illuminated samples spectra exhibit interference effects due to the thin $\mathrm{SiO}_{2}$ layer coating on the polycarbonate surface. As is demonstrated in Figure 3, the amplitude and location of these fluctuations (ripples) can be shifted or changed depending on the laser irradiation. 


\begin{tabular}{|l|l|l|l|l|l|}
\hline $\begin{array}{l}\text { Incident dose } \\
\left(\mathbf{J} / \mathbf{~ c m}^{2}\right)\end{array}$ & $\begin{array}{l}\text { Time } \\
\mathbf{( s )}\end{array}$ & $\begin{array}{l}\mathbf{P} / \mathbf{A} \\
\left(\mathbf{m W} / \mathbf{c m}^{2} \mathbf{)}\right.\end{array}$ & $\begin{array}{l}\text { Spot Size } \\
\left(\mathbf{c m}^{2} \mathbf{)}\right.\end{array}$ & $\begin{array}{l}\text { Power } \\
(\mathbf{m w})\end{array}$ & $\begin{array}{l}\text { Wavelength } \\
(\mathbf{n m})\end{array}$ \\
\hline 16.80 & 90 & 188.4 & 0.695 & 130 & 532 \\
\hline 16.80 & 75.5 & 224.6 & 0.695 & 155 & 665 \\
\hline 16.80 & 83.5 & $5.37 \times 10^{-2}$ & 0.695 & 140 & 980 \\
\hline
\end{tabular}

TABLE 1 The power of sources, spot size and calculated irradiation time for ID of $16.8 \mathrm{~J} / \mathrm{cm}^{2}$.

\begin{tabular}{|l|l|l|l|l|l|}
\hline $\begin{array}{l}\text { Incident dose } \\
\mathbf{J} / \mathbf{~ c m}^{2}\end{array}$ & $\begin{array}{l}\text { Time } \\
\mathbf{( s )}\end{array}$ & $\begin{array}{l}\mathbf{P} / \mathbf{A} \\
\left(\mathbf{m W} / \mathbf{c m}^{2} \mathbf{)}\right.\end{array}$ & $\begin{array}{l}\text { Spot Size } \\
\left(\mathbf{c m}^{2}\right)\end{array}$ & $\begin{array}{l}\text { Power } \\
(\mathbf{m W})\end{array}$ & $\begin{array}{l}\text { Wavelength } \\
(\mathbf{n m})\end{array}$ \\
\hline 25.20 & 90 & 279.5 & 0.465 & 130 & 532 \\
\hline 25.2 & 75.5 & 333.3 & 0.465 & 155 & 665 \\
\hline 25.2 & 83.5 & 301.0 & 0.465 & 140 & 980 \\
\hline
\end{tabular}

TABLE 2 The power of sources, spot size and calculated irradiation time for ID of $25.20 \mathrm{~J} / \mathrm{cm}^{2}$.

\begin{tabular}{|l|l|l|l|l|l|}
\hline $\begin{array}{l}\text { Incident dose } \\
\left(\mathbf{J} / \mathbf{~ c m}^{\mathbf{2}}\right)\end{array}$ & $\begin{array}{l}\text { Time } \\
\mathbf{( s )}\end{array}$ & $\begin{array}{l}\mathbf{P} / \mathbf{A} \\
\left(\mathbf{m W} / \mathbf{c m}^{2} \mathbf{)}\right.\end{array}$ & $\begin{array}{l}\text { Spot Size } \\
\left(\mathbf{c m}^{2} \mathbf{)}\right.\end{array}$ & $\begin{array}{l}\text { Power } \\
(\mathbf{m w})\end{array}$ & $\begin{array}{l}\text { Wavelength } \\
(\mathbf{n m})\end{array}$ \\
\hline 50.35 & 90 & 603.4 & 0.232 & 130 & 532 \\
\hline 50.35 & 75.5 & 668.1 & 0.232 & 155 & 665 \\
\hline 50.35 & 83.5 & 603.4 & 0.232 & 140 & 980 \\
\hline
\end{tabular}

TABLE 3 The power of sources, spot size and calculated irradiation time for ID of $50.35 \mathrm{~J} / \mathrm{cm}^{2}$

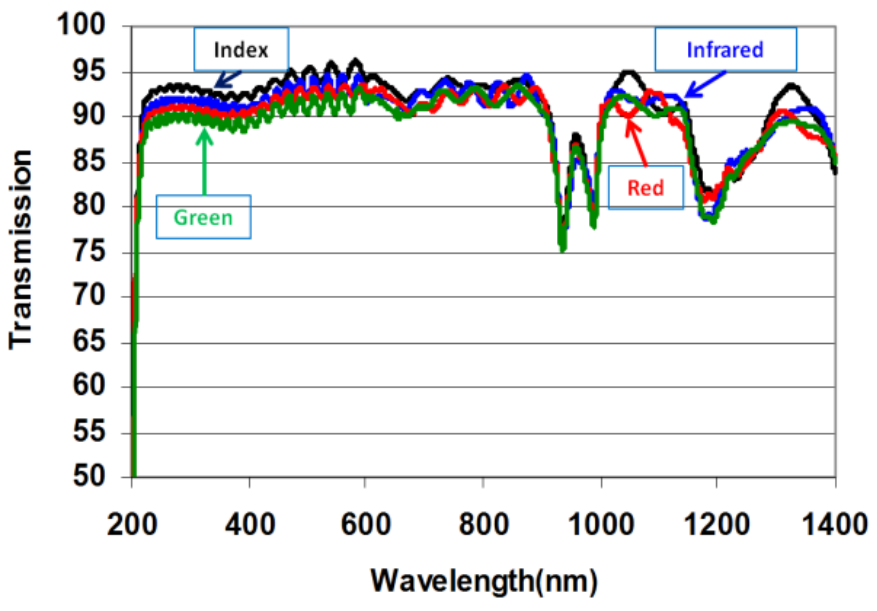

FIG. 3 The transmission spectra in UV-IR region for films, before and after irradiation with an energy density of $16.80 \mathrm{~J} / \mathrm{cm}^{2}$.

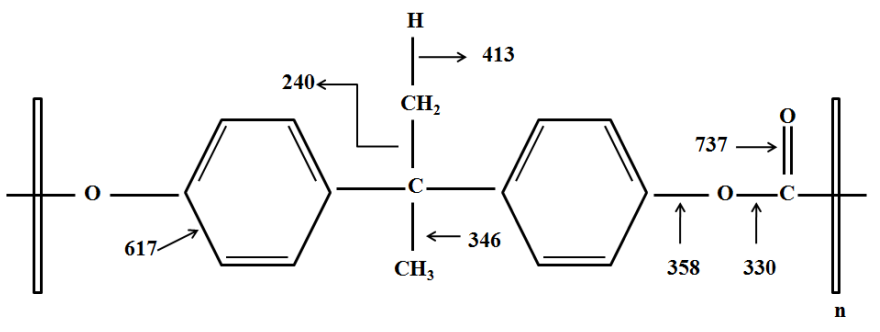

FIG. 4 Bond dissociation energy of polycarbonate in $\mathrm{kJ} / \mathrm{mol}$ [21].

The chemical structure of PC polymers and the dissociation energies of various chemical bonds in polycarbonates were examined, indicating photo-thermal and photo-chemical ablation may happen by illuminating the surface of PCs by coherent, visible light (Figure 4).
In Figure 4, the weakest bond is $\mathrm{CH} 2-\mathrm{C}\left(\sim 4 \times 10^{-19} \mathrm{~J}\right)$ followed by O-CO [21]. The dissociation energy of the $\mathrm{C}-\mathrm{C}$ bond in benzene rings is twice that of these two chemical bonds. These values of dissociation energy confirm that the $532 \mathrm{~nm}$ laser, with photon energy of $4 \times 10^{-19} \mathrm{~J}$, is able to cleave the $\mathrm{CH} 2$ side chain from the polycarbonate spine. By illuminating the surface with $532 \mathrm{~nm}$ (green), chain cleaving occurs and because of the resulting oxidation, the $\mathrm{C} / \mathrm{O}$ ratios of the illuminated polycarbonate is slightly lower than that of the index sample. As a result of chain cleaving, the Si atom of the coating layer has the opportunity to form a bond with a carbon atom located between two benzene rings. Therefore, Si-C bonds are being formed at the interface of the $\mathrm{SiO}_{2}$ layer and the polycarbonate surface. Furthermore, a Si atom can form a very weak bond with an oxygen atom of the carbonate group. The laser can break the Si-O bond at the interface of the polycarbonate and $\mathrm{Sio}_{2}$ layer. Consequently, visible laser beams are at their most effective at the interface of the coated layer and the polycarbonate surface. All of these phenomena can cause changes in the thickness of the coated layer, its refractive index and the morphology of the sample surface. Moreover, in the laser interaction with the polycarbonate, thermal effects can occur by non-resonant excitation of vibrational and rotational modes in polycarbonate [22]-[24]. These thermal effects can cause deformation in the polymer surface. The results are given in more details at Table 1.

Next, the energy density was increased to $25.20 \mathrm{~J} / \mathrm{cm}^{2}$. The spectra of the OT factors for all illuminated samples and for the index samples are presented in Figure 4. When comparing Figures 3 and 5, the dependence of OT and its fluctuations with energy density and wavelength are readily seen. The decrease in the OT factor of all illuminated samples is much more pronounced in comparison with the previous case, which can be attributed to surface damage of the samples. Following the same protocol, a summary of the effects of 


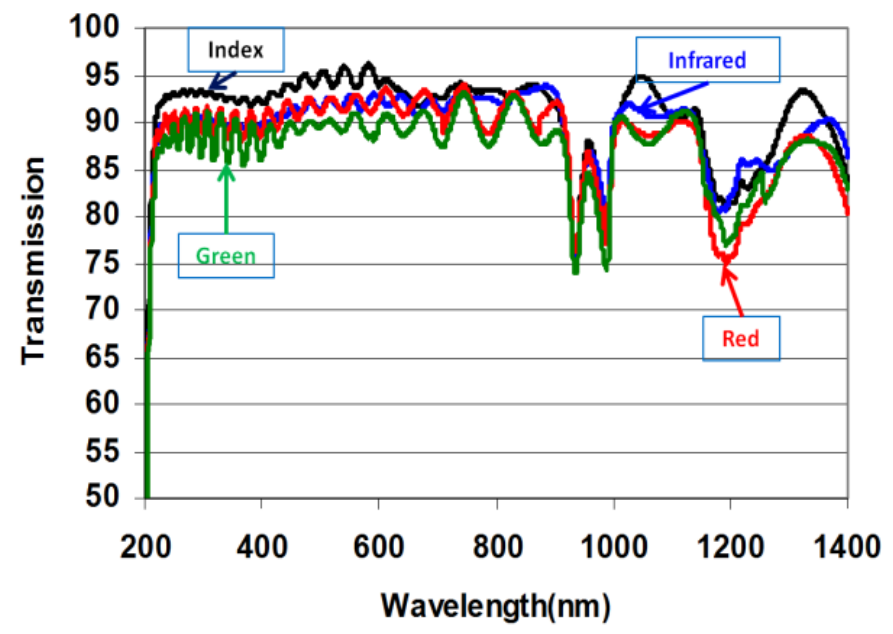

FIC. 5 The transmission spectra in UV-IR region for films before and after irradiation with an energy density of $25.20 \mathrm{~J} / \mathrm{cm}^{2}$.

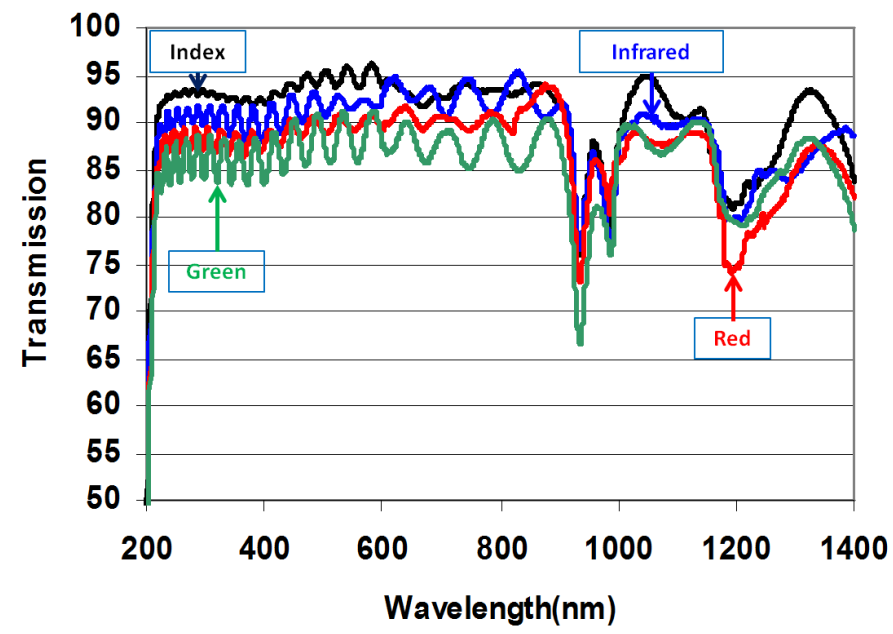

FIG. 6 The transmission spectra in UV-IR region for films before and after irradiation with an energy density of $50.35 \mathrm{~J} / \mathrm{cm}^{2}$.

three lasers with energy density of $25.20 \mathrm{~J} / \mathrm{cm}^{2}$ for three regions of wavelengths are given in Table 2. Again, the $532 \mathrm{~nm}$ laser beam is the most effective and $980 \mathrm{~nm}$ is the least effective light source for creating a change in the OT factor. At two wavelengths (1053 nm, $1328 \mathrm{~nm}$ ), significant changes can be detected for all illuminated samples when compared with the index sample.

Finally, the energy density was increased to $50.30 \mathrm{~J} / \mathrm{cm}^{2}$. As is shown in Figure 6, the OT factor has the largest decrease compared with the previous cases. In accordance with the previous protocol, a summary of results is given in more details in Table 3.

One of the important phenomena that clearly visible from Figures 3,5 and 6 is the decrease of the transmission accompany with a slight shift of transmission peak toward higher wavelength for samples that are irradiated by IR laser. Regarding a PC monomer structure, it is clear that in analyzing its NIR spectrum, the vibrational motion of $\mathrm{C}=\mathrm{O}, \mathrm{CH} 3$ and $\mathrm{CH}$ aromatic groups must be considered. It is best explained by the local mode approximation [25]-[27].
The local mode model predict the second, third and fourth harmonics of the $\mathrm{CH} 3$ stretching bonds $(\Delta v=2,3$ and 4$)$ at $6000 \mathrm{~cm}^{-1}, 8500 \mathrm{~cm}^{-1}$ and $11000 \mathrm{~cm}^{-1}$. The third harmonics of $\mathrm{C}-\mathrm{H}$ stretching bond is observed approximately at $11500 \mathrm{~cm}^{-1}$ in the NIR spectrum of PC [25]. Therefore, exposing PC material by visible to near infrared coherent beam may cause chemical changes on the surface structure. Additionally, a decrease in optical transmission and a slight shift toward higher wavelength can be detected in PC spectra due to the mode excitations [25]-[27].

Another phenomenon which is observed in Figures 3, 5 and 6 relates to the fluctuation on transmission spectrum of index sample. It is out of phase compared with the fluctuation in OT spectra of other samples that are irradiated by lasers. It can be related to an alteration in their thickness due to the laser irradiation [28]-[33]. The morphological alterations in a layer thickness due to the laser irradiation is discussed in Section 3.2 .

\subsection{Morphological characterization}

The morphological characterization of surfaces can be illustrated using atomic force microscopy-AFM images. The modifications of PC surfaces illuminated by $532 \mathrm{~nm}, 665 \mathrm{~nm}$ and $980 \mathrm{~nm}$ beams (ID: $50.30 \mathrm{~J} / \mathrm{cm}^{2}$ ) and the index sample (without irradiation) are shown in Figure 7. The roughness value of a surface can be determined by $S_{a}, S_{q}, S_{p}, S_{v}, S_{y}$ and $S_{m}$ which are the arithmetical mean height of the surface, the root mean square height of the surface, maximum peak height of the surface, maximum depth of valleys, range difference between the peak and the valley value and the mean value of roughness, respectively. These parameters are given by following standard equations:

$$
\begin{aligned}
S_{a} & =\frac{1}{M N} \sum_{k=0}^{M-1} \sum_{L=0}^{N-1}\left|z\left(X_{k}, Y_{L}\right)\right| \\
S_{q} & =\sqrt{\frac{1}{M N} \sum_{K=0}^{M-1} \sum_{L=0}^{N-1}\left[Z\left(X_{K}, Y_{L}\right)\right]^{2}} \\
S_{m} & =\frac{1}{M N} \sum_{K=0}^{M-1} \sum_{L=0}^{N-1} Z\left(X_{K}, Y_{L}\right) \\
S_{y} & =S_{p}-S_{v}
\end{aligned}
$$

As is shown in Figure 7, there is no significant difference between the surface morphology of the index sample and the one irradiated by IR (laser emitting $980 \mathrm{~nm}$ ). However, as the photon energy increases, the changes in the surface morphology become more pronounced.

\section{CONCLUSIONS AND SUMMARY}

We have shown that visible light can influence the surface roughness of thin PCs as summarized in Tables 4-6. The OT factor of the illuminated samples is decreased. As was envisaged, shorter wavelengths (higher photon energy) cause greater modifications to the surface morphology. By increasing the energy density, the roughness factor of the illuminated samples was increased. The appearance of more fluctuations in the OT spectra of illuminated samples (particu- 
Transmission spectra region $/ 16.80 \mathrm{~J} / \mathrm{cm}^{2}$

\section{$200 \mathrm{~nm}-500 \mathrm{~nm}$}

OT factor for all illuminated samples is decreased by $5 \%$ compared with the index sample.

The OT of the sample illuminated by green has the least value but the fluctuation (ripples) in its OT is the minimum.

The samples illuminated by $980 \mathrm{~nm}$ and $665 \mathrm{~nm}$ beams have almost similar changes in their OT values.

\section{$500 \mathrm{~nm}-1000 \mathrm{~nm}$}

Effective changes could not be observed for samples illuminated by the red and near infrared laser beams. However, the effect of $532 \mathrm{~nm}$ green laser on OT factor is slightly more than the other sources.
1000 nm-1400 nm

At $1055 \mathrm{~nm}$ and $1328 \mathrm{~nm}$, significant changes can be detected compared with the other wavelengths in the range of $1000 \mathrm{~nm}-1400 \mathrm{~nm}$. The value of the OT has decreased for all illuminated samples.

TABLE 4 Details of transmission spectral region of PCS/ $16.80 \mathrm{~J} / \mathrm{cm}^{2}$.

\begin{tabular}{|c|c|c|}
\hline \multicolumn{3}{|l|}{ Transmission spectral region/ $25.20 \mathrm{~J} / \mathrm{cm}^{2}$} \\
\hline $200 \mathrm{~nm}-500 \mathrm{~nm}$ & $500 \mathrm{~nm}-1000 \mathrm{~nm}$ & $1000 \mathrm{~nm}-1400 \mathrm{~nm}$ \\
\hline $\begin{array}{l}\text { The OT factor of all samples illumi- } \\
\text { nated by lasers is decreased. } \\
532 \mathrm{~nm} \text { laser causes the most signifi- } \\
\text { cant changes in OT factor. }\end{array}$ & $\begin{array}{l}\text { The infrared laser creates no signifi- } \\
\text { cant changes in OT factor compared } \\
\text { with the index sample. } \\
532 \mathrm{~nm} \text { and } 650 \mathrm{~nm} \text { lasers cause effec- } \\
\text { tive changes in fluctuations (ripples) } \\
\text { seen in the OT spectra that could be } \\
\text { related to microscopic changes in the } \\
\text { surface roughness. }\end{array}$ & $\begin{array}{l}\text { At } 1055 \mathrm{~nm} \text { and } 1328 \mathrm{~nm} \text {, more ob- } \\
\text { servable changes can be detected and } \\
\text { the value of the OT has decreased for } \\
\text { samples illuminated by } 532 \mathrm{~nm} \text { and } \\
650 \mathrm{~nm} \text { lasers. }\end{array}$ \\
\hline
\end{tabular}

TABLE 5 Details of transmission spectral region of $P C S / 25.20 \mathrm{~J} / \mathrm{cm}^{2}$.

\begin{tabular}{|c|c|c|}
\hline \multicolumn{3}{|l|}{ Transmission spectral region/ $50.30 \mathrm{~J} / \mathrm{cm}^{2}$} \\
\hline $200 \mathrm{~nm}-500 \mathrm{~nm}$ & $500 \mathrm{~nm}-1000 \mathrm{~nm}$ & $1000 \mathrm{~nm}-1400 \mathrm{~nm}$ \\
\hline $\begin{array}{l}\text { The green laser ( } 532 \mathrm{~nm} \text { ) is the most } \\
\text { effective in changing the OT factor of } \\
\text { PC samples. } \\
\text { The } 980 \mathrm{~nm} \text { laser is the least effective } \\
\text { source. The effects of } 665 \mathrm{~nm} \text { laser be- } \\
\text { tween the two limits created by green } \\
\text { and infrared lasers. } \\
\text { The ripples in the OT factor are more } \\
\text { significant compared with the previ- } \\
\text { ous cases. }\end{array}$ & $\begin{array}{l}\text { The changes in the OT factor remains } \\
\text { as was observed in the } 200-500 \mathrm{~nm} \\
\text { range. } \\
\text { The other significant effects are the } \\
\text { peak of changes by green encountered } \\
\text { by the anti-node of changes caused by } \\
\text { the IR beam (opposite effects). }\end{array}$ & $\begin{array}{l}\text { Green and red lasers ( } 532 \mathrm{~nm} \text { and } \\
665 \mathrm{~nm} \text { ) have similar effects on the } \\
\text { OT factors. These effects are more pro- } \\
\text { nounced at } 1055 \mathrm{~nm} \text { and } 1328 \mathrm{~nm} \text {. } \\
\text { The effect of the IR beam }(980 \mathrm{~nm} \text { ) on } \\
\text { the OT is the least. At } 1390 \text {, a consid- } \\
\text { erable change in OT can be seen. This } \\
\text { change can be even detected in two } \\
\text { previous incident doses for this par- } \\
\text { ticular wavelength. }\end{array}$ \\
\hline
\end{tabular}

TABLE 6 Details of transmission spectral region of PCS/ $50.30 \mathrm{~J} / \mathrm{cm}^{2}$.

larly at higher energy densities) which can be related to the roughness of the surface as is shown in Figure 7 was another result of interest. At an energy density of $16.80 \mathrm{~J} / \mathrm{cm}^{2}$ ripples start to appear, however, by increasing the energy density to $25.20 \mathrm{~J} / \mathrm{cm}^{2}$ and $50.35 \mathrm{~J} / \mathrm{cm}^{2}$, the amplitude of the ripples is increased, suggesting strong dependence on photon energy, time of exposure, and beam diameter.

In conclusion, surface morphology and the optical quality of PCs surfaces is shown to be related to many factors. Nevertheless, illuminating these surfaces with lasers emitting photons with wavelengths less than $532 \mathrm{~nm}$ and energy densities higher than $50.00 \mathrm{~J} / \mathrm{cm}^{2}$ can increase the surface roughness and decrease the OT factor.

\section{References}

[1] P. R. Sundararajan, "Conformational features of bisphenol-A polycarbonate" Can. J. Chemistry 63, 103-106 (1985).

[2] Z. S. Geretovszky, B. Hopp, I. Bertoti, and I. W. Boyd, "Photodegradation of polycarbonate under narrow band irradiation at $172 \mathrm{~nm}$ " Appl. Surf. Sci. 186, 85-90 (2002).

[3] C. Charitidis, A. Laskarakis, S. Kassaveties, and C. Gravalidis, “0ptical and nanomechanical study of anti-scratch layer on polycarbonate lenses" Superlattice. Microstr. 36, 171-179 (2004).

[4] T. Schmauder, K. D. Nauenburg, K. Kruse, and G. Ickes, "Hard coating by plasm CVD on polycarbonate for automotive and optical applications" Thin Solid Films 502, 270-274 (2006). 

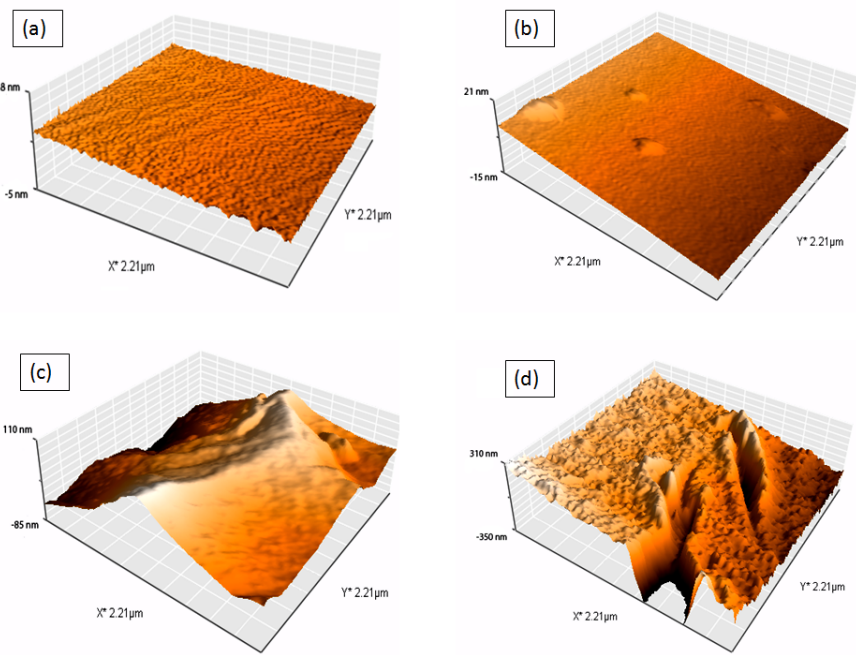

FIG. 7 AFM image of PC samples -index and illuminated by lasers $\left(50.35 \mathrm{~J} / \mathrm{Cm}^{2}\right)$. (a) index (b) illuminated by $980 \mathrm{~nm}$ (c) illuminated by $650 \mathrm{~nm}$ (d) illuminated by $532 \mathrm{~nm}$

[5] M. D. Migahed, and H. M. Zidan, "Influence of uv-irradiation on the structure and optical properties of plycarbonate fims" Curr. Appl. Phys 6, 91-96 (2006).

[6] D. Bellus, P. Hrdiovic, and Z. Manasek, "Photoinitiated rearrangements in poly [2, 2-propane bis(4-phenyl earbonate)]" J. Polym. Sci. Pol. Lett. 4, 1-5 (1966).

[7] A. Rivaton, "Recent advances in bisphenolpolycarbonatephotodegradation" Polym. Degrad. Stabil. 49, 163-179 (1995).

[8] M. R. Adams, and A. Garton, "Surface modification of bisphenol-A polycarbonate by far-uv radiation.port I :in vacuum" Polym. Degrad. Stabil. 41, 265-273 (1993).

[9] M. R. Adams, and A. Garton, "Surface modification of bispheno-A polycarbonate by far-uv radiation.partll : in air" Polym. Degrad. Stabil. 42, 145-151 (1993).

[10] R. Ramani, and C. Ranganathaian, "Degradation of acrylonitrilebutadiene-styrene and polycarbonate by uv-irradiation" Polym. Degrad. Stabil. 69, 347-354 (2000).

[11] M. Diepens, and D. Cijsman, "Photodegradation of bisphenol-A polycarbonate" Polym. Degrad. Stabil. 92, 397-706 (2007).

[12] A. V. Zverev, I. G. Neivestnyi, N. L. Shwartz, and Z. Shyanovitskaya, "Lattice Monte Carlo model of $\mathrm{SiO}_{x}$ layer" Nanotech. Rus. 3, 368377 (2007).

[13] A. G. Erlat, B.-Ch. Wang, and R. J. Spontak, "Morphology and gas barrier of thin $\mathrm{SiO}_{x}$ coatings on polycarbonate : Correlations with plasma-enhanced chemical vapor deposition conditions" J. Mater. Res 15, 704-717 (2000).

[14] N. Tomozelu, "Effects of UV photon irradiation on $\mathrm{SiO}_{x}(0<x<$ 2) structural properties" Appl. Surf. Sci. 253, 376-380 (2006).

[15] G. Aichmayr, D. Toet, M. Mulato, P. V. Santos, A. Spangenberg, S. Christiansen, M. Albrecht, and H. Pstrunk, "Lateral grain growth during the laser interference crystallization of A-Si" Phys. Status. Solidi A 166, 659-666 (1998).

[16] A. Janotta, Y. Dikce, M. Schmidt, C. Eisele, M. Statzmann, M. Lusberg, and L. Houben, "Light-induced modification of a-siox:Laser crystallization" J. Appl. Phys. 95, 4060-4068 (2004).
[17] B. J. Garrison, and R. Srinivasan, "Laser ablation of organic polymers: microscopic models photochemical and thermal processes" J. Appl. Phys. 57, 2909-2914 (2009).

[18] E. Spyratou, M. Makropoulo, and A. A. Serafetinides, "Study of visible and mid-infrared laser ablation mechanism of PMMA and intraocular lenses : experimental and theoretical results" Laser Med. Sci. 23, 179-188 (2008).

[19] A. A. Serafetinides, C. D. Skordoulis, M. I. Makropoulou, and A. K. Kar, "Picoseconds and sub picosecond visible laser ablation of optically transparent polymers" Appl. Surf. Sci. 135, 276-284 (1998).

[20] D. M. Bubb, S. L. Johnson, R. Belmont, K. E. Schriver, R. F. Haghland Jr, C. Antonacci, and L. S. Yeung, "Mode specific effects in resonant infrared ablation and deposition of polystyrene" Appl. Phys. A 83, 147-151 (2006).

[21] B. Jang, and C. A. Wilki, "The thermal degradation of bisphenol a polycarbonate in air" Thermochim. Acta. 426, 73-84 (2005).

[22] G.B. Blanchet, "Laser ablation and the unzipping of addition polymer" J. Appl. Phys. 80, 4082-4089 (1996).

[23] R. Srinivasan, and B. Braren, "Ultraviolet laser ablation of organic polymers" Chem. Rev. 89, 1303-1316 (1989).

[24] Y. G. Ying-Ling, and B. J. Grrison, "Photo chemical induced effect in material ejection in laser ablation" Chem. Phys. Lett. 364, 237-243 (2002).

[25] U. John, and K. P. R. Nair, "Near IR overtone spectral investigations of cyclohexanol using local mode model-evidence for variation of anharmonicity with concentration due to hydrogen bonding" Spectrochimica Acta A 61, 2555-2559 (2005).

[26] Sh. Shi, and W. H. Miller, "A semiclassical model for intramolecular vibrational relaxation of local mode overtone in polyatomic molecules" Theor. Chem. Acc. 68, 1-21 (1985).

[27] B. R. Henry, "The local mode model and overtone spectra: a probe of molecular structure and conformation" Acc. Chem. Res. 20, 429435 (1987).

[28] V. Pander, S. K. Tripathi, and A. Kumar, "A study of optical parameters of amorphous se 70 - Te30-x Ag $x$ thin films before and after heat treatment" J. Ovonic. Res. 3, 29-38 (2007).

[29] D. Poelman, and P F. Smet, "Methods for the determination of optical constant of thin films for single transmission measurements a: critical review" J. Phys D Appl. Phys. 36, 1850-1857 (2003).

[30] J. Sanchez-Gonzales, A. Diaz-Parralejo, A. Lortiz, and F. Guberzeau, "Determination of optical properties in nano structured thin films using the swan pole methode" Appl. Surf. Sci. 252, 6013-6017 (2003).

[31] I. Boerascu, M. Pereira, M. J. M. Gomes, and M. I. G. Frreira, "Structural and optical characterization of NB - doped pzt 65/35 thin films grown by Sol - gel and laser ablation techniques" J. 0ptoelectron Adv. M. 2, 602-609 (2000).

[32] V. Lyubin, M. Klebanor, A. Arsh, L. Shpiro, and B. Sfez, "Classy AS40 Se25 Te35 films with high regractive inde" J. Optoelectron Adv. M. 8, 2077-2079 (2006).

[33] G. Gomes, 0. M. Ozkendir, H. Kavak, and Y. Ufuktepe, "Structural, and optical properties of zinc oxide thin films prepared by spray pyrolysis methode" J. Optoelectron Adv. M. 8, 299-303 (2006). 